\title{
A SURVEY OF INDUSTRIAL HERITAGES IN THE CONTEXT OF WATER BASINS: EASTERN BLACK SEA, CENTRAL MEDITERRANEAN AND NORTHERN AEGEAN
}

\author{
GÜLFERAH ÇORAPÇIOĞLU \\ Faculty of Engineering and Architecture, Istanbul Arel University, Turkey
}

\begin{abstract}
Traditional watermills are examples of industrial heritage that work with water power. This study has been carried out in order to develop approaches that will ensure the sustainability of conservation for water mills of Turkey. After the field studies carried out in sub basins of Eastern Black Sea, Central Mediterranean and Northern Aegean Water Basins, 44 water mills that were built for grain milling have been determined. When these structures are considered in the context of the geographical properties of the water basin in which they are located, it is seen that the factors effecting the architectural formation and the distribution of the watermills are dependent upon the climate and topography of the basin. Also, sustainability of original function varies depending upon their architectural formation and the distribution. Accordingly, these structures that should be structurally, functionally and legally conserved shall have a conservation approach not only building based, but rather basin scaled. This study developed conservation recommendations on basin scale.
\end{abstract}

Keywords: cultural heritage, industrial heritage, watermill, water power, grain milling.

\section{INTRODUCTION}

Being one of the earliest examples of industrial heritage, watermills are traditional structures used for production that work with the principle of generation of energy using hydraulic power. They are also examples of cultural heritage that reveal important information about the community life and technological advancements of the time they were built. They are complex systems, composed of buildings, hydraulic works and mechanisms [1]. Watermills are industrial heritages and they are in scope of previously mentioned charters and principles. The International Committee for the Conservation of Industrial Heritage, (TICCIH) adopted Nizhyn Tagil charter in 2003, and decisions were made for protection of industrial heritage. In this charter, industrial heritage was defined as remains of industrial culture which are of historical, technological, social, architectural or scientific value; and its scope was stated as buildings and machinery, workshops, mills, factories, places related to energy systems and places used for social activities related to industry [2]. As stated in Dublin Principles, "human skills and knowledge involved in old industrial processes are a critically important resource in conservation and must be considered in the heritage evaluation process" [3]. Traditional watermills exist in two types, depending on whether they have horizontal (turbine type) or vertical water-wheels [4]. Vertical water-wheel systems function through the harnessing of water's kinetic energy by a vertical water-wheel emplaced on a stream. The power obtained with these systems is then transferred to the production tools through horizontal shaft and gear systems [5]. The movement of horizontal (turbine type) water-wheels, on the other hand, involve the passage of the water through a chute to form a water jet, which is directed to pallets of a horizontal wheel, thereby allowing the water jet's kinetic energy to be harnessed. This type of system has generally been used for grain production. As examples of technologies that make use of water power, there are many examples of water mills in Anatolia stretching as far back as the Roman Era [6]. 
In Turkey, necessary attention is not paid to water mills and many water mills are unpreserved and gradually falling into ruin due to disuse. International heritage policies must be applied for water mills in Turkey too [7]. This study aimed to ensure the preservation and sustainability of traditional water mills in Turkey, and to allow these water mills to become heritage for future generations. The preservation of water mill structures along with their original function is proposed, as well as the continuation of these cultural heritages together with their tangible and intangible values.

This paper presents an individual research on traditional watermills in Turkey. 44 watermills that were built for grain milling have been determined after field studies carried out in the basins of "Eastern Black Sea", "Central Mediterranean" and "Northern Aegean" Water Basins of Anatolia. The study areas were evaluated by visual methods and meetings were performed with the local people to evaluate the social and economic aspects; geographical location, topographic features, historical texture, demographic structure, ownership status, source of living and water sources. Watermills are investigated with regards to their mill house and working systems, based on their distribution, structural features of mill house, their plan types, systems, system elements and original function status. When these structures are considered in the context of the geographical properties of the water basin in which they are located, it is seen that the factors effecting the architectural formation and the distribution of the mills are dependent upon the geographical location and topography of the basin. Also, sustainability of original function varies depending upon their architectural formation and the distribution. Accordingly, these structures that should be structurally, functionally and legally conserved shall have a conservation approach not only building based, but rather basin scaled. In this context, this paper emphasizes the importance of conservation studies in the basin case.

\section{METHODOLOGY}

The studies regarding the water mills were performed in the three different basins of Anatolia. The research has been developed in stages. In the first step; determination and evaluation of the study areas were performed. In the second stage, the legal documents (regional map, hydrologic network) related to the water basins were obtained from official institutions. In last stage; evaluation and documentation of the water mills were performed.

\subsection{Determination and evaluation of the study areas}

In the study, it is planned to conduct research in the water basins, where annual flow rates are intensive. Based on its topography, Turkey is divided into 25 different hydrologic basins. The total annual flow through these areas has been calculated as 186 billion $\mathrm{m}^{3}$. The first basin selected for study is Eastern Black Sea Basin, number 22; the annual total flow of this basin is 14.90 billion $\mathrm{m}^{3}$ and ranks as the area with the $2^{\text {nd }}$ highest flow. The second basin is Central Mediterranean Basin, number 9 and ranks as the area with the $4^{\text {th }}$ highest flow. The annual total flow of this basin is 11.06 billion $\mathrm{m}^{3}$ [5].

In order to strengthen the research findings, the study was supported by a third water basin; and the Northern Aegean Basin, number 4, which has an history of intensive agricultural activity, was added to the study area. The field studies carried out in sub basins of Eastern Black Sea, Central Mediterranean and Northern Aegean Water Basins (Fig. 1).

For delimitation of basin areas; the intensity of the water mills, the preservation of the original structure and accessibility factors have been decisive. Accordingly; the studies regarding the water mills of the "Eastern Black Sea Basin" were performed on the "Sulak, Arili, Caglayan and Hara River" sub-basins. The studies of the "Mediterranean Basin"; were 
performed on the "Doyran and Candir River" sub-basins. And the studies regarding the "Northern Aegean Basin" were performed on the "Kara Menderes River" sub-basin. The sub-basins were evaluated by visual methods in the context of geographical location, topographic features, historical texture, demographic structure, source of living and meetings were performed with the local people to evaluate the social and economic aspects. Water mills located within the basin have been investigated regarding location, distribution, architectural formation of the mill house, working systems and sustainability of original function and meetings were performed with local craftsmen specializing in the construction of local structures.

\subsection{Data collection studies}

No evaluation and documentation studies have been performed to date on water mills within the areas of this study. The hydrologic networks were requested from the official institutions for hydrological mapping of the water mills to be documented. The regional maps of the basins were provided by the General Directorate of Cartography. The numbering of regional map of the Eastern Black Sea Water Basin is F-46 and Sulak Arili, Caglayan and Hara River sub-basins is F-46-d2 (Fig. 2). The numbering of regional map of the Central Mediterranean Water Basin is O-24-O-25, Doyran River sub-basins are O-24-b2/ O-25-a1 and Candir River sub-basin are O-24-b3 / O-24-c2 / O-25-a1 /O-25-a3 (Fig. 3).

The numbering of regional map of the Northern Aegean Basin is I-17 and Kara Menderes River sub-basin is I-17-a2 / I-17-a3 / I-17-a4 / I-17-b1 (Fig. 4).

The hydrologic network of the river basin was obtained from the General Directorate of the Turkish State Water Works (Fig. 5).

\subsection{Evaluation and documentation of the water mills}

As a first step of the activities for documenting the watermills, coordinates of the mills were determined to identify their exact geographical location. They were marked on the regional map and on the hydrologic network. As a second step, the current status of the water mills was documented by digital photography. And as a third and final step, the interior and exterior of the water mill buildings were examined, and layout plans, plans, cross-sections and visual sketches were prepared in order to describe the water mills current conditions with scaled drawings.

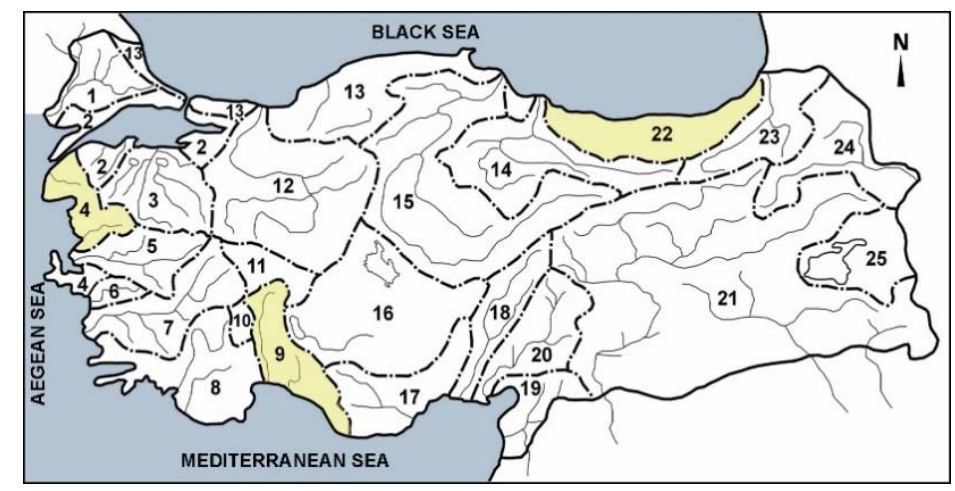

Figure 1: Hydrologic areas of Turkey. (Corapcioglu, 2014.) 


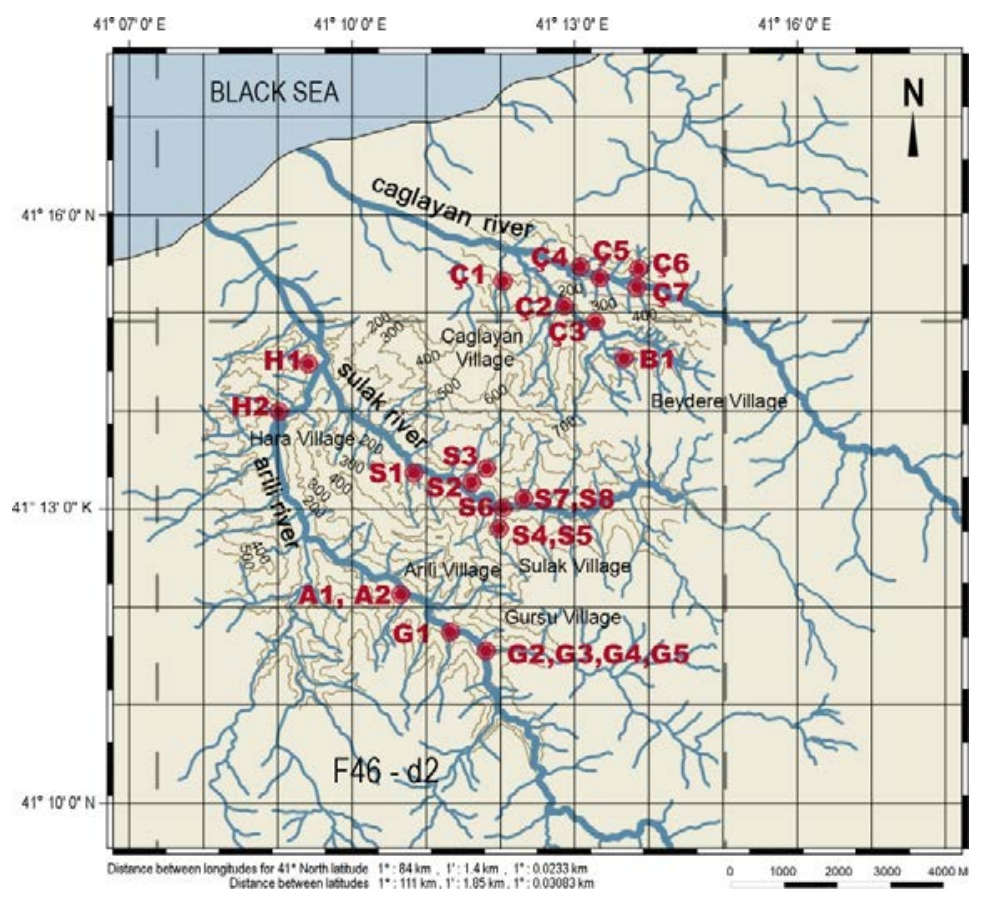

Figure 2: Map of the Eastern Black Sea Basin. (Corapcioglu, 2014.)

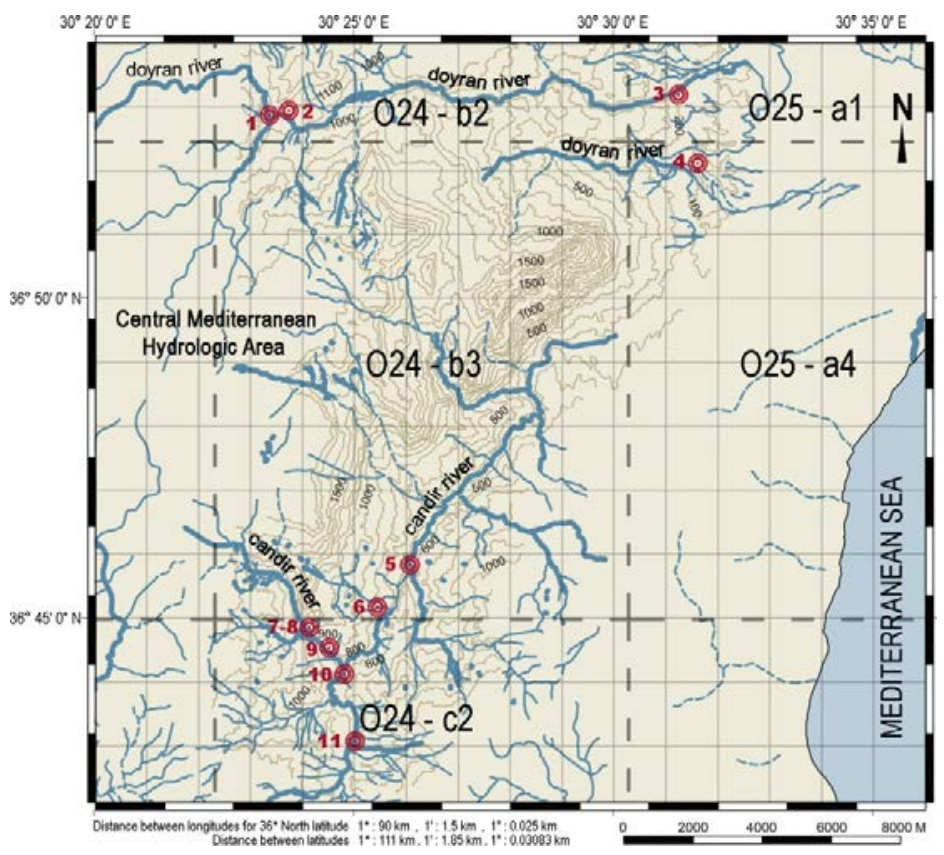

Figure 3: Map of the Mediterranean Basin. (Corapcioglu,2014.) 


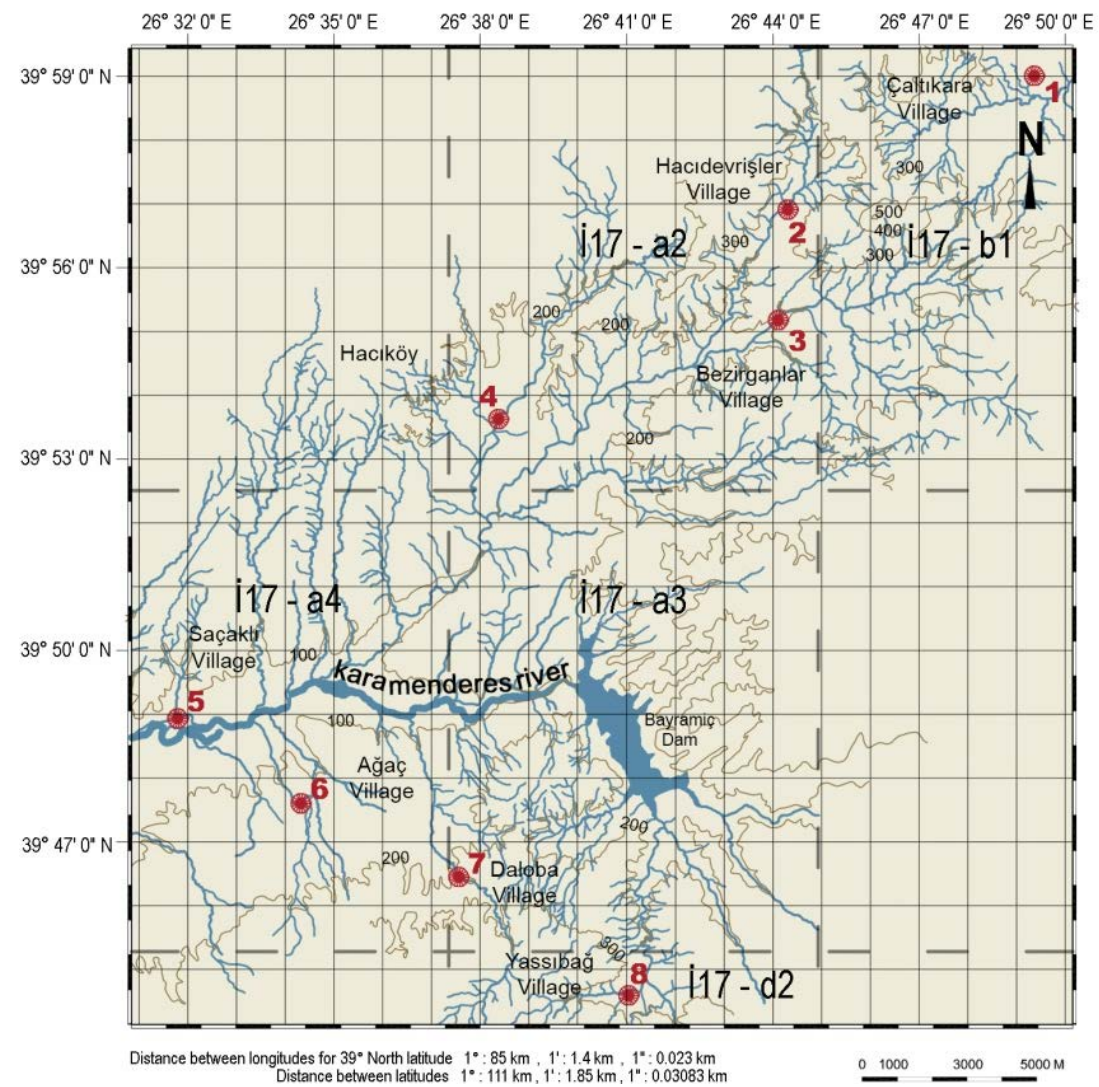

Figure 4: Map of the Northern Aegean Basin. (Corapcioglu, 2014.)

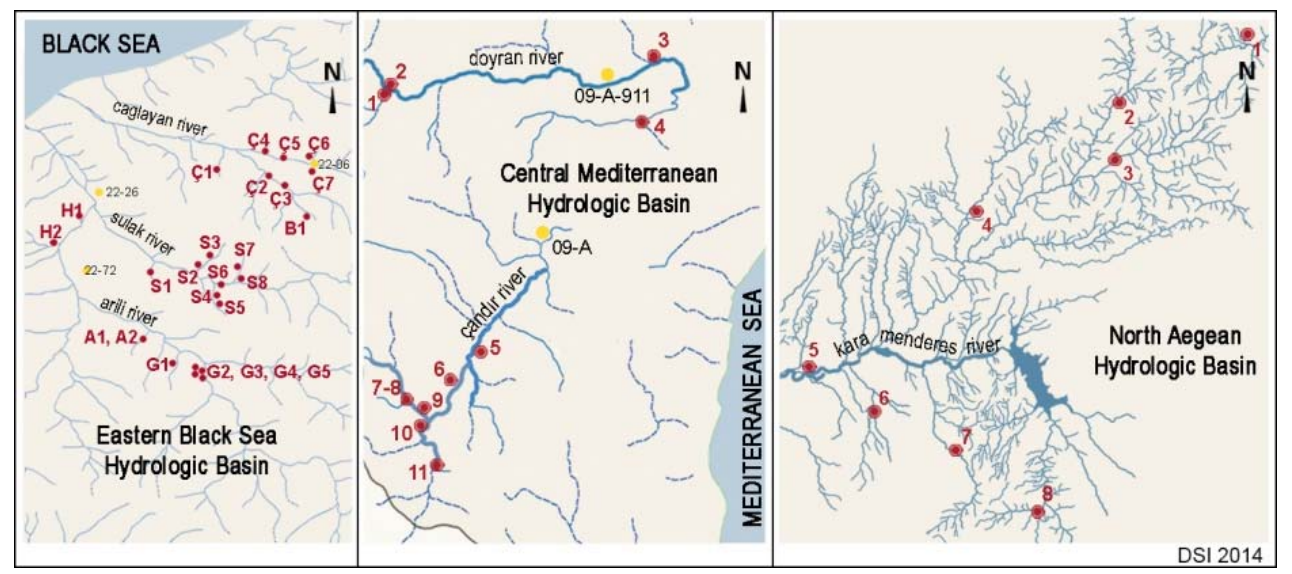

Figure 5: Hydrologic network of the river basins. (Corapcioglu, 2014.) 


\section{RESULTS AND DISCUSSION}

44 water mills have been determined as a result of field studies carried out in sub basins of Eastern Black Sea, Central Mediterranean and Northern Aegean Water Basins. They were investigated with regards to their mill house and working systems, based on their distribution, structural features of the mill house, their plan types, systems, system elements and original function status. And they were evaluated in terms of their common and different characteristics according to the location of their river basin.

\subsection{Evaluation of the water mills regarding their common characteristics}

It was found out that the determined water mills are all (turbine type) horizontal wheel mills used for grain production that operated on the principle of harnessing energy from the flow of water (Fig. 6).

These watermills are located in rural areas close to river valleys. Depending on the topographical features of their basins, they are built on stream beds that enable sufficient head to rotate the water wheel and sufficient slope for water discharge (Fig. 7).

However, when these structures are considered in the context of the geographical properties of the water basin in which they are located, it is seen that the factors effecting the architectural formation of the mills are dependent upon the geographical location and topography of the basin.

\subsection{Evaluation of the watermill in the context of river basin characteristics}

The studies regarding the water mills of the "Eastern Black Sea Basin" were performed on the Sulak, Arili, Caglayan and Hara River sub-basins; of the 25 mills that are located in an

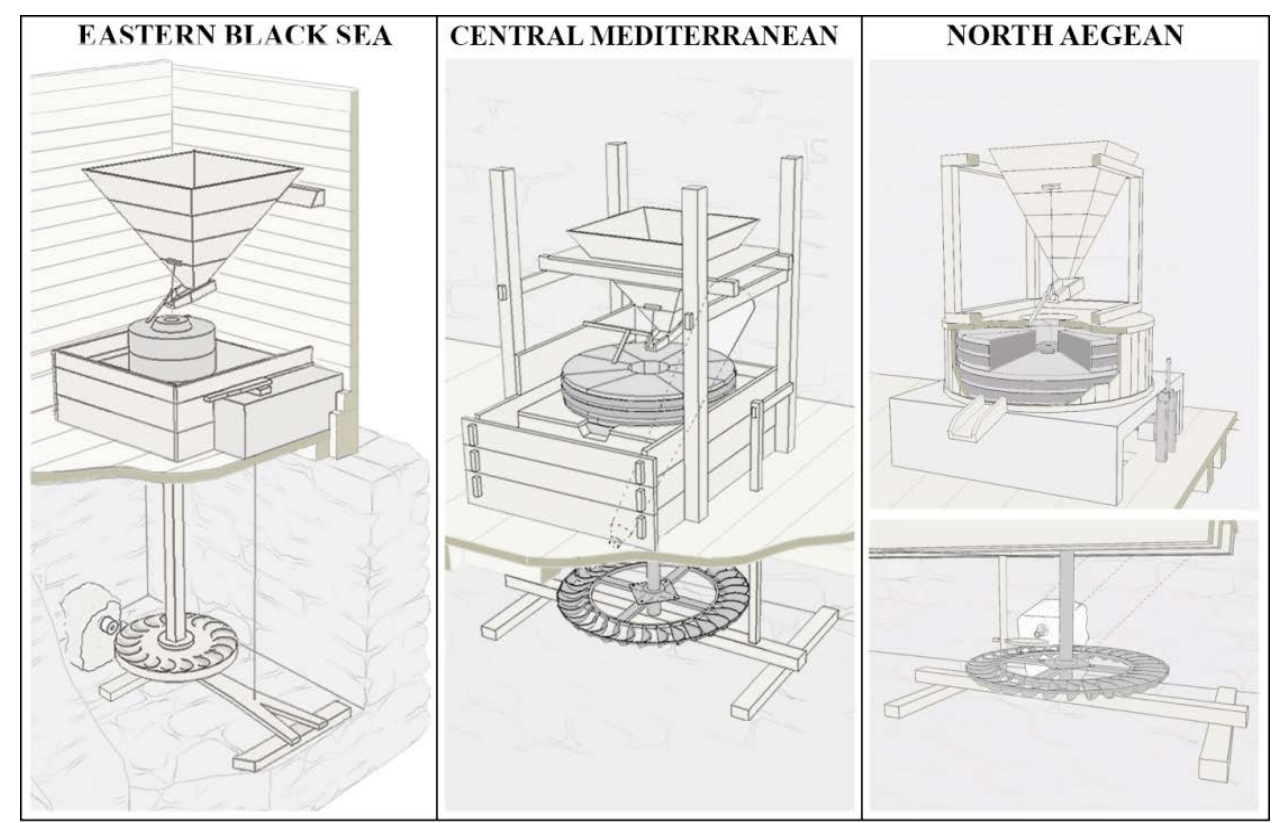

Figure 6: Watermill systems from different water basins. (Corapcioglu, 2014.) 
area of $85 \mathrm{~km}^{2}$ including six villages in this basin, 21 are still functioning. Fig. 2 shows the distribution of these water mills.

The studies regarding the water mills of the "Mediterranean Basin" were performed on the Doyran and Candir River sub-basins; of the 11 water mills that are located in an area of $250 \mathrm{~km}^{2}$ including five villages in the basin are all functionless. Fig. 3 shows the distribution of these water mills.

The studies regarding the water mills of the "Northern Aegean Basin" were performed on the "Kara Menderes River" sub-basin. Of the eight water mills that are located in an area of $550 \mathrm{~km}^{2}$ including eight villages in Aegean Basin, one is still functioning, although it is damaged. Rest of the water mills are functionless. Fig. 4 shows the distribution of the water mills.

According to quantitatively supported results of original research; when these facts are interpreted considering the geographical features of the water basins; it was determined that the distribution and architectural features of the watermills depend on climatic and topographical features of their basins and that their functional sustainability has developed accordingly.

In Eastern Black Sea, watermills built for grinding corn. They operate throughout the year. They are small scaled and can serve limited number of houses. They are united with villages and they are part of daily life for villagers.

In Aegean and Mediterranean regions, mills were built in large scales, for grinding wheat. They can function six months in a year, can serve to multiple villages. They are built apart from settlements and need a specialized miller to be operated (Fig. 8).

\subsection{Comparison of the watermills in the context of river basin characteristics}

Eastern Black Sea Basin has four season precipitation character. Therefore corn, a plant that requires plenty of water during cultivation can be grown without irrigation. As a consequence, watermills are designed to grind corn, which is course grained, and their mill stones are single piece, have small diameter and rotate fast. The rest of the mill system elements are designed in accordance with the mill stone. In this basin, the water mills can operate in all 12 months of a year. Production is done for short-term needs and storage of the product is not required. As a consequence, mills are built with small capacity. The topography of Eastern Black Sea Basin consists of sloped and scattered fields due to dense river network. This resulted in scattered settlements. Watermills are built in accordance with settlements and rivers and therefore they are small scaled and built frequently. A watermill can serve usually four or five houses. Today, these small scaled watermills are still a part of daily life. Villagers themselves can grind for their own needs. A specialized miller profession does not exist in this region. Today their original function is sustained.

In Aegean and Mediterranean basins, summer months are arid. The region is suitable for wheat agriculture, since wheat requires arid conditions in maturation and harvest periods. As a consequence, mills are designed for grinding wheat. In order to grind wheat which is fine grained, mill stones that have larger diameter, rotate slower, grind finer are used. Rest of the mill system elements are designed in accordance with the mill stone. Because of arid summer months, production is possible during six months in a year. Therefore, when operating, the watermills must produce more wheat flour than required, and store the excess product. For this reason, the watermills are built large scaled. In Aegean and Mediterranean basins, collective settlements exist. Watermills are built outside of settlements, in a central location that can serve to multiple nearby villages. They were operated by millers. Today, the milling 
profession has become economically unsustainable due to fast production techniques that evolve with developing technology. The watermills are abandoned and functionless.

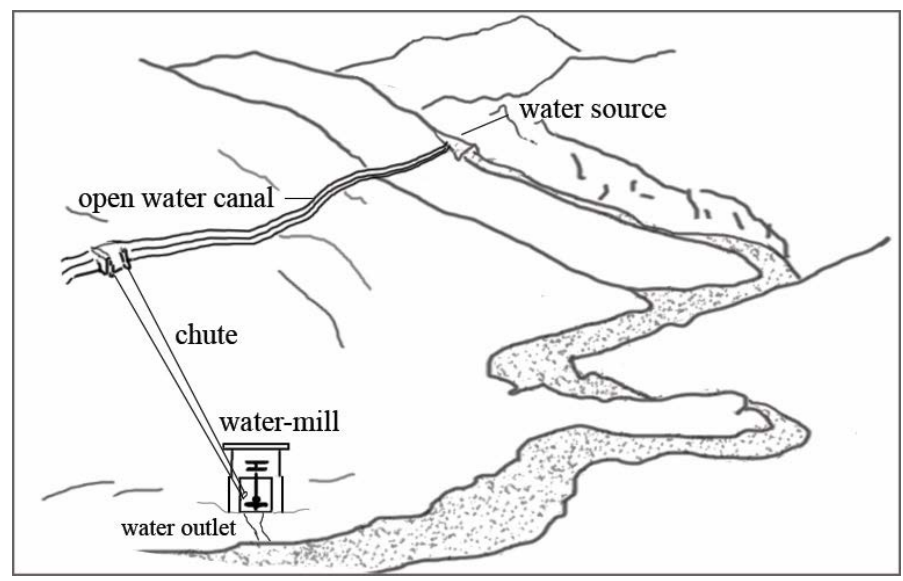

Figure 7: Horizontal (turbine type) watermill. (Corapcioglu, 2014.)

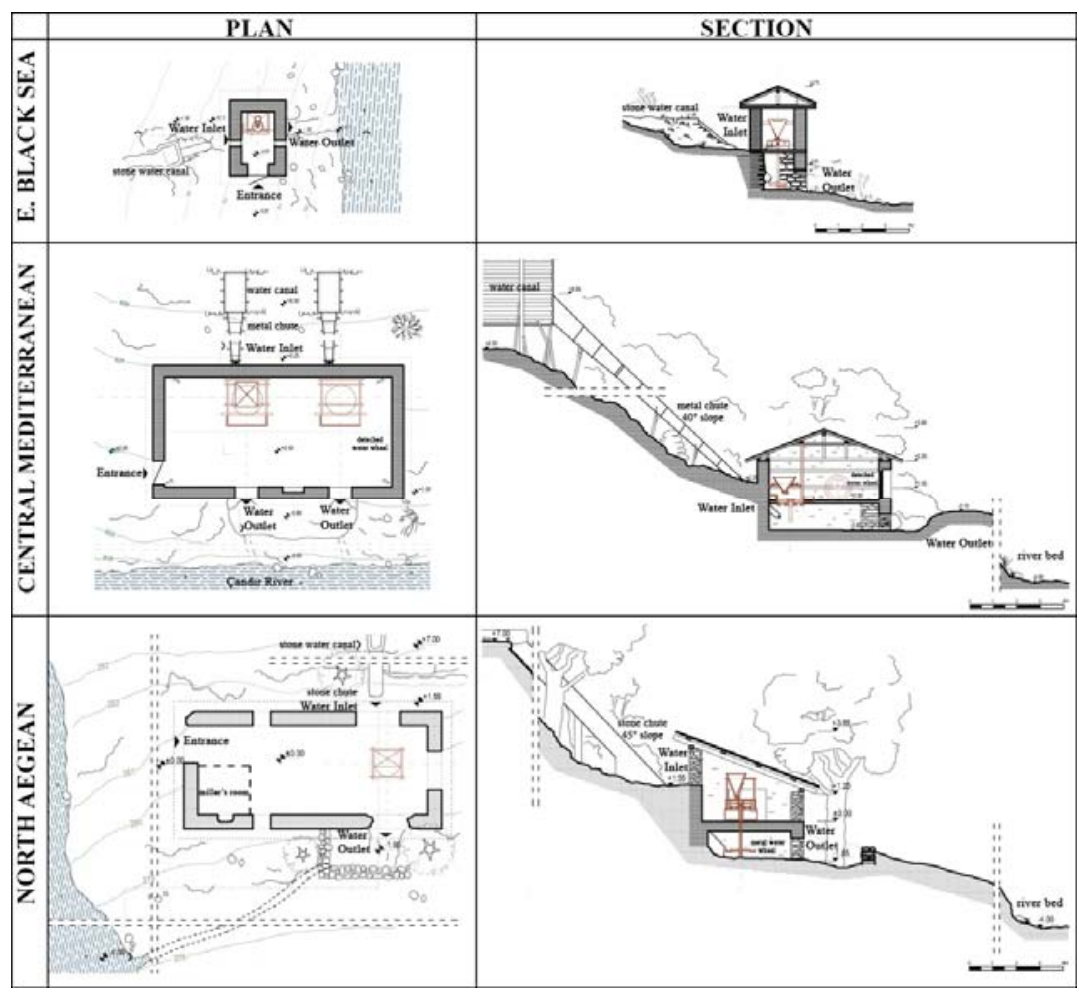

Figure 8: Watermill buildings from different water basins. (Corapcioglu, 2014.) 


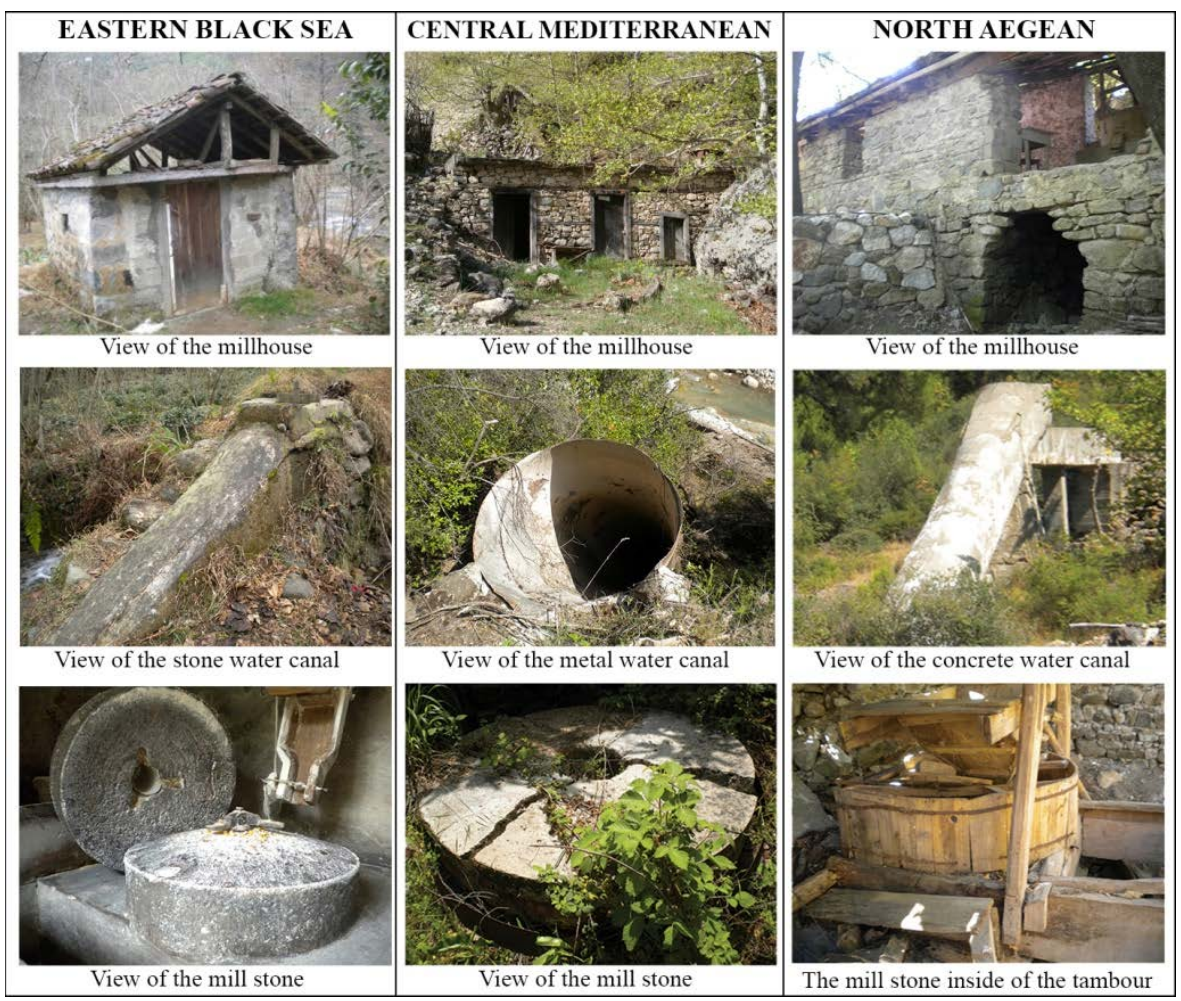

Figure 9: Examples of watermill from different basin. (Corapcioglu, 2014.)

As a result; precipitation characteristics of the basin depend on climatic features and has effect on stream flow. Annual active periods of watermills depend on amount of stream flow. Capacity and size of watermills are planned considering annual production needs and active periods. Depending on topographical features of the basin, river systems create wide or scattered terrains and accordingly settlement patterns are in dispersed or compact forms. Distribution and location of watermills are planned in accordance with settlement forms. Location and distribution of watermills determine their operation conditions. These conditions affect functional sustainability of the watermills (Fig. 9).

\section{CONCLUSION}

In addition to the physical existence of the watermill which constitute important examples of the traditional production culture and technology history, it is necessary to protect them in the context of sustainability of the mill and milling cultures formed by years of knowledge and experience. However, according to the conclusion that the mills are sustainable with different characteristics in different basin, it has been understood that it is necessary to evaluate each of the basins within themselves and to develop a conservation approach in this context. In this respect, the history of the region, the state of preservation, the potential for re-activation and the interplay of economic support should be investigated and a protection proposal should be developed accordingly. The analysis of each of the basins according to their geographical characteristics, determination of the natural and cultural values in the 
vicinity of the settlement, the analysis of the traditional lifestyle and the means of living of the community in the context of social and economic characteristics, are points to be evaluated for the basin-specific conservation proposals.

As indicated in the result section; in Eastern Black Sea, small scale watermills are united with villages. They are part of daily life for villagers and today their original function is sustained. In this region to ensure the sustainability of the authentic cultural heritage, it is important to raise awareness among the local community regarding the conservation of architectural heritage

However, in Aegean and Mediterranean regions, mills were built in large scales. They are built apart from settlements and need a specialized miller to be operated. Unfortunately, now the milling profession has become economically unsustainable. Therefore, original function of watermills is not sustained. In order to preserve the original function of these traditional production structures, the region needs to become attractive and the mills have to be adapted to cultural tourism activities that show conventional production techniques and lifestyles.

The main approach to adopt in order to ensure the sustainability of traditional production structures should involve preparing projects by obtaining financial support from national and international conservations funds, creating areas that will draw the attention of local and foreign tourists by developing ecological and touristic road maps, and developing revolving fund institutions that will allow maintenance and repair costs to be covered by the income earned through these activities.

Finally, ensuring the sustainability of water mill structures will have the following positive socio-economic impacts. They will revitalize local villages and economies and will encourage the reuse and retention of heritage buildings in rural areas for promoting socioeconomic revitalization at a local level. They will contribute to the preservation of traditional crafts and activities, thus ensuring the continuation of traditional knowledge as well as stability in rural communities. They will contribute to a return in the art of building traditional structures, while also maintaining the heritage of such rural and vernacular structures.

\section{REFERENCES}

[1] Sorge, F. \& Genchi, G., Essays on the History of Mechanical Engineering. Springer: Italy, pp. 81-99, 2014.

[2] TICCIH, The Nizhny Tagil Charter for the Industrial Heritage, Online. http://international.icomos.org/18thapril/2006/nizhny-tagil-charter-e.pdf. Accessed on: Dec. 2016.

[3] ICOMOS-TICCIH, The Dublin Principles, Online. http://www.icomos.org/Paris2011/ GA2011 ICOMOS. Accessed on: Feb. 2016.

[4] Çorapçıŏlu G., A research of method about documentation and conservation of water mills in the example of Black Sea Region. Mimar Sinan Fine Arts University, Institute of Science and Technology, Istanbul, 2015.

[5] Forbes, R.J., Power A history of technology Volume 2, ed. C. Singer \& E.J. Holmyard, The Clarendon Press: Oxford, 1957.

[6] Danisman, G., A survey of turbine-type water-mills in the Bolu Region of the Central Anatolian Plateau. Journal of the Faculty Architecture Middle East Technical University, 3, pp. 17-37, 1997.

[7] Çorapçıoğlu G., Conservation of the traditional water mills in the Mediterranean region of Turkey. Journal of Cultural Heritage Management and Sustainable Development, Emerald press, 6(3), pp. 287-315, 2016.

[8] DSI, Data from the Turkish state hydraulic works, Turkey, 2014. 